\title{
Building Quranic stories ontology using MappingMaster domain-specific language
}

\author{
Rusul Yousif Al-Salhi, Abdulhussein Mohsin Abdullah \\ Department of Computer Science, College of Computer Science and Information Technology, University of Basrah, Basrah, Iraq
}

\begin{tabular}{l}
\hline \hline Article Info \\
\hline Article history: \\
Received Mar 6, 2021 \\
Revised Jul 16, 2021 \\
Accepted Aug 4, 2021 \\
\hline
\end{tabular}

Keywords:

MappingMaster DSL

Ontology population

ORM

OWL

Quran ontology

Semantic web

SPARQL query

\begin{abstract}
The Holy Quran, due to it is full of many inspiring stories and multiple lessons that need to understand it requires additional attention when it comes to searching issues and information retrieval. Many works were carried out in the Holy Quran field, but some of these dealt with a part of the Quran or covered it in general, and some of them did not support semantic research techniques and the possibility of understanding the Quranic knowledge by the people and computers. As for others, techniques of data analysis, processing, and ontology were adopted, which led to directed these to linguistic aspects more than semantic. Another weakness in the previous works, they have adopted the method manually entering ontology, which is costly and time-consuming. In this paper, we constructed the ontology of Quranic stories. This ontology depended in its construction on the MappingMaster domain-specific language (MappingMaster DSL) technology, through which concepts and individuals can be created and linked automatically to the ontology from Excel sheets. The conceptual structure was built using the object role modeling (ORM) modeling language. SPARQL query language used to test and evaluate the propsed ontology by asking many competency questions and as a result, the ontology answered all these questions well.
\end{abstract}

This is an open access article under the CC BY-SA license.

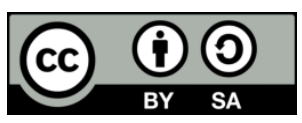

\section{Corresponding Author:}

Rusul Yousif Al-Salhi

Department of Computer Science, University of Basrah

Basrah, Iraq

Email: r.alsalhee6@gmail.com

\section{INTRODUCTION}

Today, access to information plays an important role in gaining knowledge and is considered an important feature for the user. Despite the role that the traditional web plays in publishing and sharing information, the user cannot obtain or retrieve the information in a correct and easy way. Therefore, information sharing and retrieval have led to the construction of the ontology that is a major part of the semantic web.

The semantic web is an extension of the current web. It refers to the work on transforming the current web from being a huge repository in which information is collected in an unorganized and untidy manner, to an organized digital repository or a huge database linked between them by links based on understanding the meanings, and relationships that make its interconnectedness with the information wellconnected, and this makes searching for information and making use of it easily. The semantic web requires that the terms have a clear meaning in order for machines to be able to process and present the information on the web automatically, and whoever provides these meanings is the ontology.

Ontology is "the specification of conceptualizations used to help programs and humans to share knowledge [1]". Ontology provides a large number of potential benefits in representing and processing 
knowledge, including the separation of domain knowledge from application knowledge, defining or determining the nature of reality through its definition of terms, concepts, categories, and entities in a specific domain with the aim of modeling and formulating relationships between them, and the reuse of domain knowledge for a variety of applications. The most important language of semantic web used in the construction of the ontology is web ontology language (OWL). OWL is a semantic coding language designed to create and publishing the ontology on the internet, adopted by the World Wide Web consortium, and is a major development in the semantic web march. To build any ontology for a specific field of knowledge, there are no fixed steps or methodology that can be followed to build the ontology, but only general questions [2] that we should answer to right begin are:

a) What is the ontology's domain that will covered?

The proposed ontology will cover the Holy Quran stories domain including person, event, place, surah, animals, book, chapter, verses, and relationships with each other.

b) For what we use the ontology?

For many applications dealing with Quran, such as Interpretation, information retrieval, information extraction, text mining.

c) What types of questions will the ontology answer to?

Information about prophet, messenger, animals, righteous, infidel, nation, and event. Such as names of the prophet, miracles, punishment, honoring, and others.

d) Who will maintain and utilize the ontology?

The researchers were interested in the study of Holy Quran.

Several researchers interested in building ontologies of Islamic knowledgebase in different languages such as English, Malay, Indonesian and other languages. Based on our observation of a literature review that close to proposed field of research, we found that there are few ontologies in the English language compared to the Arabic language as shown in Figure 1 and these previous works were not clear and covered part of the Qur'an.

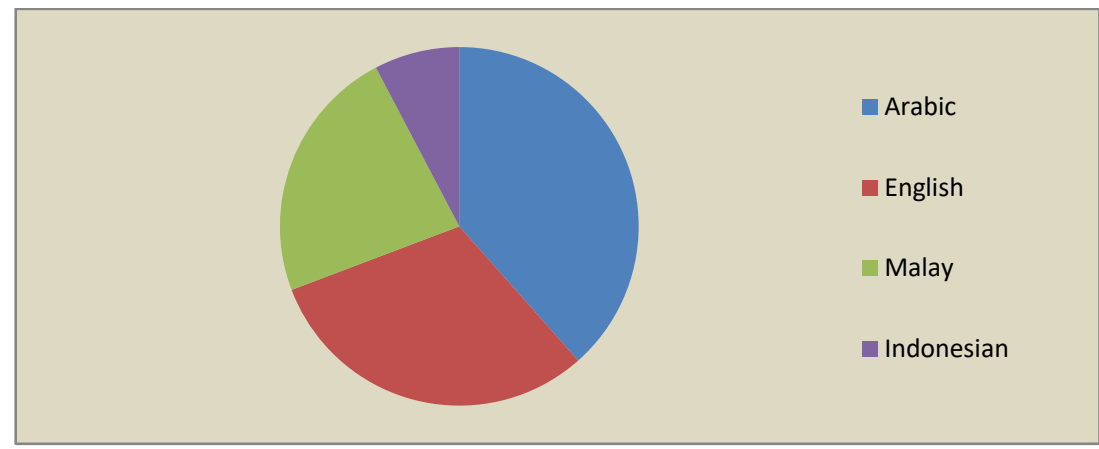

Figure 1. Representation languages of most work interested in Quran

So, we proposed building English ontology which is interested in Holy Quran stories included the stories of the prophets, messengers, righteous people, infidels, animals, and events that were included in the stories, including miracles, God punishment and others. The following is a brief overview of the relevant work with shown result in Table 1, beginning with the most recent:

The several study in [3], [4] developed an English methodology for automatic extraction of the concepts in the Holy Quran with ontology learning techniques. To develop Solat (prayer) ontology, they extract the verses which have the word of Solat. The Solat ontology is based on information took from domain experts and does not cover all subjects in the Quran. The ontology documentation in [3] generated using TopBraid editor. The most critical obstacles or weaknesses that they faced were that the ontology did not answer the competency questions expected of them, and there is a similarity to some of the verses related to concepts and needs a clearer future explanation. After that in [4], the authors developed the ontology using protégé editor and evaluated it by SPARQL query and the result was that it answered all the competency questions.

For searching the Holy Quran, Khan et al. [5] proposed ontology-based semantic knowledge. The domain of ontology focused on living creatures including animals and birds. In order to explore the proper function of ontology, the ontology was constructed using protégé and SPARQL queries.

In order to obtain a clearer understanding of the meanings of the Qur'anic terms using conventional Arabic dictionaries and a Qur'an ontology, Al-Maayah et al. in [6] developed a WordNet for Qur'an by 
creating semantic relations between words. This study was based on a rich body of prior studies, such as the work of [7] and the WordNet [8], which reveals the English language's semantic connections between words. Alromima et al. [9] proposing an ontology-based model focused on Arabic language vocabulary related to "Place Nouns" in the Holy Quran. The structure of the ontology designed using the unified modeling language (UML) language and then implemented ontology using protégé editor.

Alqahtani and Atwell [10] proposed a framework for a new semantic search tool in Arabic language called Arabic Quranic semantic search tool based on ontology (AQSST). IR techniques and semantic search techniques were applied to this tool. Hamed and Aziz [11] designed a system called QAS to retrieve information from the Holy Quran and to answer user questions accurately. This was done by classifying verses using neural network (NN) technique and the Quranic database translated into English by Abdullah Yusuf Ali.

Al-Sanasleh and Hammo [12] proposing an ontology interested in prophets and messengers in Islam from trustworthy resources includes Holy Quran and Hadith. The conceptual model that was used to construct the structure of the ontology consisted of tables of concepts, binary relations, and attributes. The ontology was represented using OWL language and a protégé editor.

Suryana et al. [13] study previous works related to the field of the Noble Qur'an, including the construction of an ontology, the development of an existing ontology, the dataset, the tools and techniques used to develop, test and population the ontology, the limitations of the works and the languages used to represent the ontology. Utomo et al. [14] proposed a framework for classifying cases of small training groups applied to question answering system (QAS). The framework they applied consisted of two phases: the training data structuring phase and the classification phase.

The remainder of the paper is organized as follows: section 2 describes the proposed ontology creation methodology. Section 3 describes the implementation and population of holy quran stories ontology. Section 4 describes the result and discussion. Finally, section 5 conclusion of the work and the future work.

Table 1. Result of previous researches

\begin{tabular}{|c|c|c|c|}
\hline Paper & Tools and Technique & Language used & Gap \\
\hline [4] & $\begin{array}{l}\text { TopBraid editor, protégé, } \\
\text { SPARQL queries }\end{array}$ & English language & $\begin{array}{l}\text { The structure of a conceptual model is not built to map } \\
\text { out the clear vision and set constraints on relationships. }\end{array}$ \\
\hline [5] & protégé and SPARQL queries & English language & $\begin{array}{l}\text { The structure of a conceptual model was not } \\
\text { constructed to draw a clear vision and set constraints on } \\
\text { relationships, and the methodology used to construct the } \\
\text { ontology was not clarified. }\end{array}$ \\
\hline [6] & $\begin{array}{l}\text { Arabic dictionaries and a } \\
\text { Qur'an ontology }\end{array}$ & $\begin{array}{l}\text { English and } \\
\text { Arabic language }\end{array}$ & $\begin{array}{l}\text { The work was limited to Quranic texts and linguistically } \\
\text { synonymous words and their translation into the } \\
\text { English language, and semantic web techniques were } \\
\text { not used in this. }\end{array}$ \\
\hline [9] & $\begin{array}{l}\text { UML language and protégé } \\
\text { editor. }\end{array}$ & Arabic Language & $\begin{array}{l}\text { The UML modeling language is used to draw the } \\
\text { conceptual model and is considered imprecise by } \\
\text { setting constraints on relationships. Do not used } \\
\text { SPARQL queries to test and evaluate the ontology }\end{array}$ \\
\hline [10] & $\begin{array}{l}\text { IR techniques and semantic } \\
\text { search techniques }\end{array}$ & $\begin{array}{l}\text { English and } \\
\text { Arabic language }\end{array}$ & The mechanism of action has not been fully clarified. \\
\hline [11] & $\begin{array}{l}\text { NN technique and the } \\
\text { Quranic database translated } \\
\text { into English by Abdullah } \\
\text { Yusuf Ali. }\end{array}$ & English language & $\begin{array}{l}\text { The dataset that was used for the terms of the Holy } \\
\text { Quran translated into the English language was ready } \\
\text { and therefore a lexical database was not built for the } \\
\text { terms that were translated into the English language. }\end{array}$ \\
\hline [12] & Protégé editor & Arabic Language & $\begin{array}{l}\text { Modeling languages are not used to graphically } \\
\text { represent the ontology. The ontology was not tested and } \\
\text { evaluated with SPARQL queries. }\end{array}$ \\
\hline [13] & & English Language & \\
\hline [14] & $\begin{array}{l}\text { Semantic analysis, feature } \\
\text { extraction, instances } \\
\text { classification Function } \\
\text { Networks algorithm }\end{array}$ & English Language & The work is still under development and testing. \\
\hline
\end{tabular}

\section{RESEARCH METHOD}

In this paper, created own methodology to follow in building the proposed ontology. Figure 2 shows the methodology that was followed to build Quran stories ontology. The methodology includes three phases:

\subsection{Phase 1: data collection phase}

In this phase, data related to the Prophets, Animals, Infidels, Nation, and Events that occurred with them such as Miracles, and so on was collected from different trustworthy Islamic knowledge sources. This 
data has been processed in three simple steps to facilitate dealing with it and use of it more. These steps included: First, searching for concepts, that can be used by building the Quranic stories ontology. Second, classification, after acquiring the concepts, it was classified into basic concepts (classes) and sub-concepts (classes), basic class such as person class that belongs to thing class and sub-class of person class such as prophet class, as shown in Table 2. Third, search for relationships, after classifying classes the relationships among these concepts (classes) were looked, so that the concepts could be linked with each other and obtain the meaning completely. After that, Excel tables were created for these concepts and their relationships to facilitate more work and obtain information in an orderly and coherent manner so that we can benefit from it later in the coming phases.

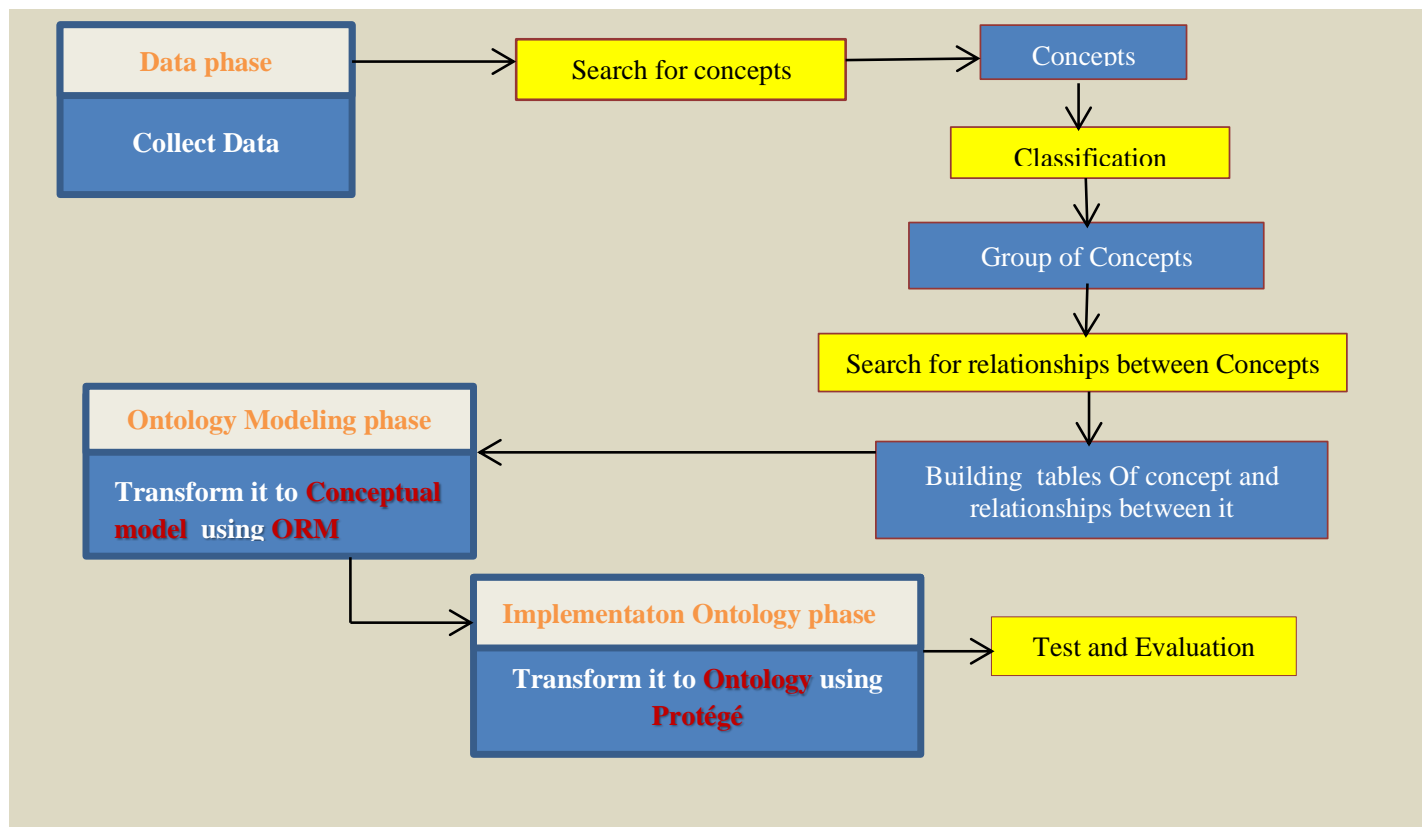

Figure 2. Ontology building methodology

Table 2. Holy quranic stories ontology classes

\begin{tabular}{|c|c|c|c|c|}
\hline Superclass & Subclass & Description & Class & No \\
\hline 1 & Person & Represent anybody has story in Quran. & $\begin{array}{l}\text { Prophet class, Messenger class, Righteou } \\
\text { class, Infidel class and Nation class. }\end{array}$ & Thing \\
\hline 2 & Animal & $\begin{array}{l}\text { Represent any bird, mammals, and } \\
\text { mentioned in Quran and has important role. }\end{array}$ & $\begin{array}{c}\text { Mammal class, Reptiles class, Bird class } \\
\text { And Insect class. }\end{array}$ & Thing \\
\hline 3 & Event & Represents everything happened by God. & $\begin{array}{l}\text { Historic class (God punishment class, } \\
\text { Honoring class, God commanded class, } \\
\text { Miracles class) and Afterlife class. }\end{array}$ & Thing \\
\hline 6 & Verses & Represent number of verses of Quran. & & Thing \\
\hline 7 & Place & Represents every village, city, and town & Mission place, live place and birth place. & Thing \\
\hline 8 & Book & Represents any book mentioned in Quran. & ............... & Thing \\
\hline 9 & Event Tool & Represents anything that caused any event. & ............... & Thing \\
\hline 10 & Date & $\begin{array}{c}\text { Represents any date mentioned in Quran or } \\
\text { history books. }\end{array}$ & $\ldots$ & Thing \\
\hline
\end{tabular}

\subsection{Phase 2: ontology modeling phase}

The ontology modeling phase is very important before starting to build ontology because it draws us a map of concepts and provides a clear and correct vision to complete the work. Representing concepts graphically is easier than representing them in (resourse description framework)/(extensible markup language) serialization format. For this reason, we have chosen object-role modeling (ORM) to represent the concepts graphically. ORM originated as a semantic modeling approach in the early 1970s, which views the world clearly in terms of objects playing roles [15], [16]. ORM is a conceptual modeling language and its constraints that impose on concepts are very similar to the in restrictions OWL language [17], [18]. This 
leads to flexibility in using this language and the ease of compatibility between it and OWL language. In Figure 3 we show conceptual model for Holy Quranic stories ontology.

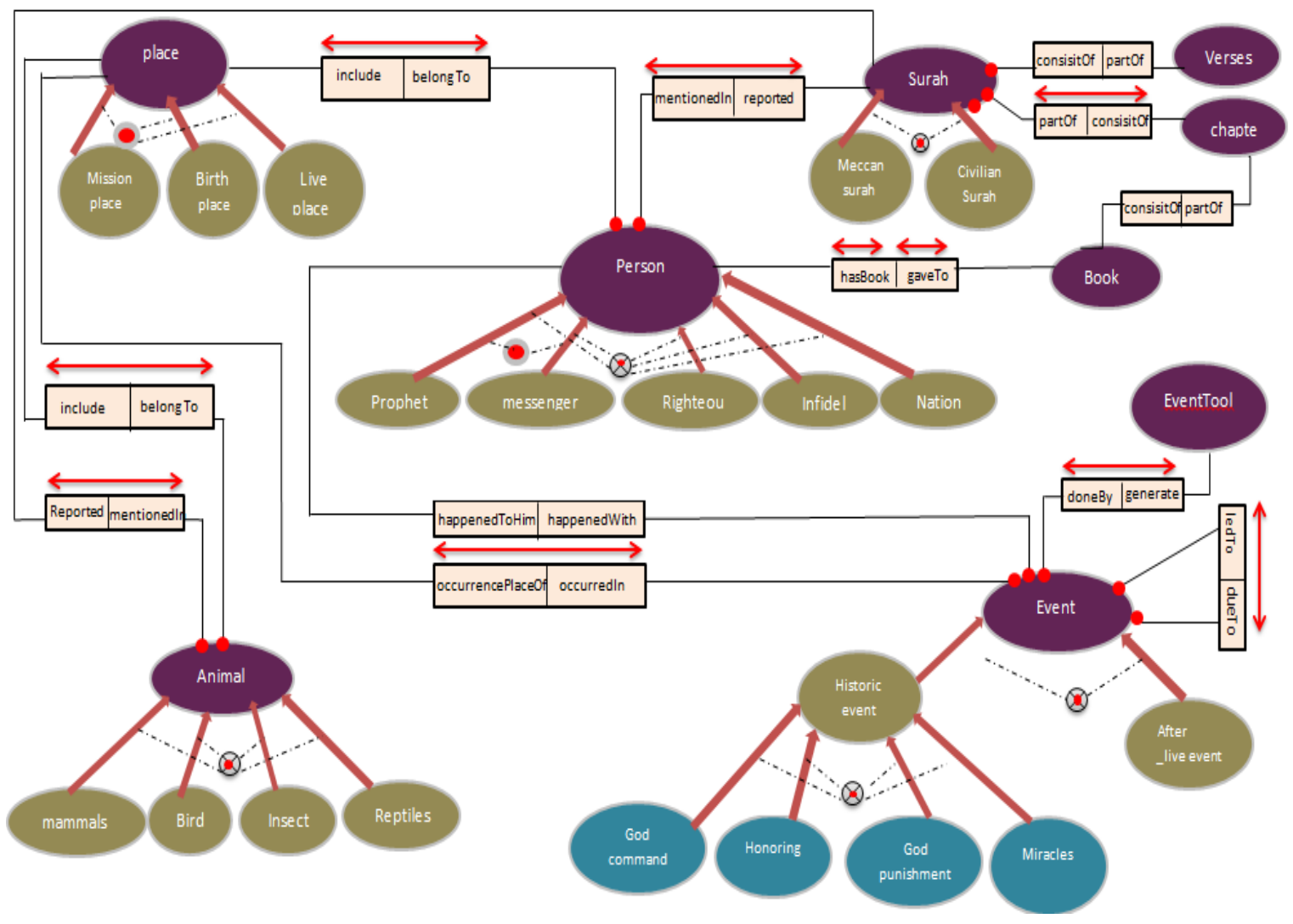

Figure 3. Conceptual model of holy quranic stories ontology

\subsection{Phase 3: implementation and population of Holy Quran stories ontology}

After completing previous phase, it became possible to start the process of building the ontology easily. Generally, an ontology consists of the concepts (classes) that are structured in a taxonomic hierarchy, these concepts are related to one another by relationships called properties or slots or roles (such as in ORM) and contain instances [19]. The properties are subject to a range of restrictions or constraints also called facts or axioms.

Generally, for the development of ontology in any field, there are three techniques: manual ontology development [2], ontology teaching (learning) [20], [21], and ontology mapping. In proposed ontology manual ontology development used and then using ontology mapping technique for populating it. Web ontology language (OWL) used to represent the ontology by protégé tool version 5.5 [22].

The ontology consisted of 31 classes have been classified to represent the proposed ontology, including Ten basic classes and twenty-one sub-classes. The Person class included five sub-classes that included: Prophet class (like the Prophet Adam), Messenger class (like the Messenger Muhammad), Infidel class (like Pharaoh), Righteous class (like Luqman) and Nation class (such as Aad and Thamud) that to which God sent the Prophets and Messengers. These classes were represented using OWL Language, which represent basic element in Semantic Web [23]. There are several approaches to build the taxonomy of concepts such as the Bottom-Up, Top-Down, Middle-Out. In proposed ontology we have followed the TopDown approach as shown in Figure 4. In OWL language, property is divided into three types [24]:

- Object property: A relation between instances (individual) of two classes. Same as property in ORM, but in OWL property may not have range and domain

- Datatype property: A relation between instances (individual) of classes and literal (values)

- Annotation property: can be used to add information (metadata).

Therefore, in this ontology, 35 object properties are proposed as in Figure 5, and 19 data type properties are proposed as in Figure 6. 


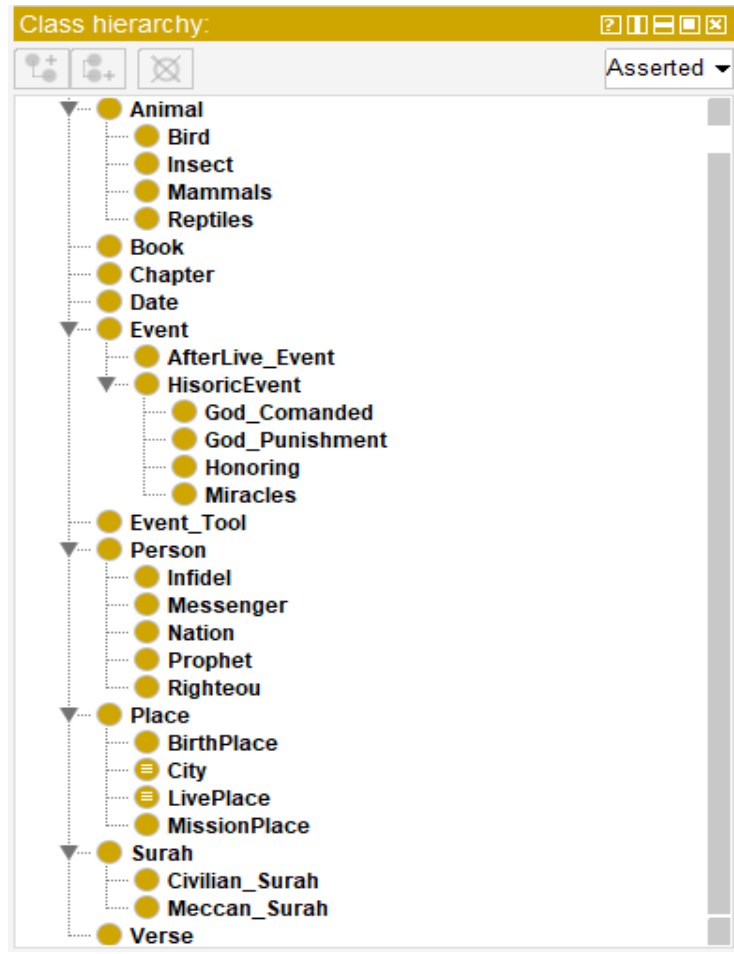

Figure 4. Taxonomy of holy quranic stories class in protégé

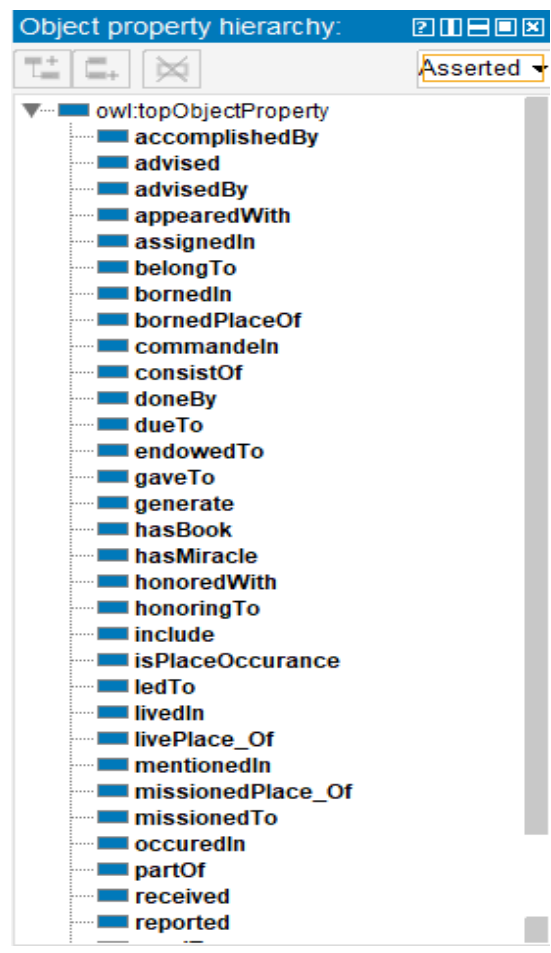

Figure 5. Holy quranic stories object properties

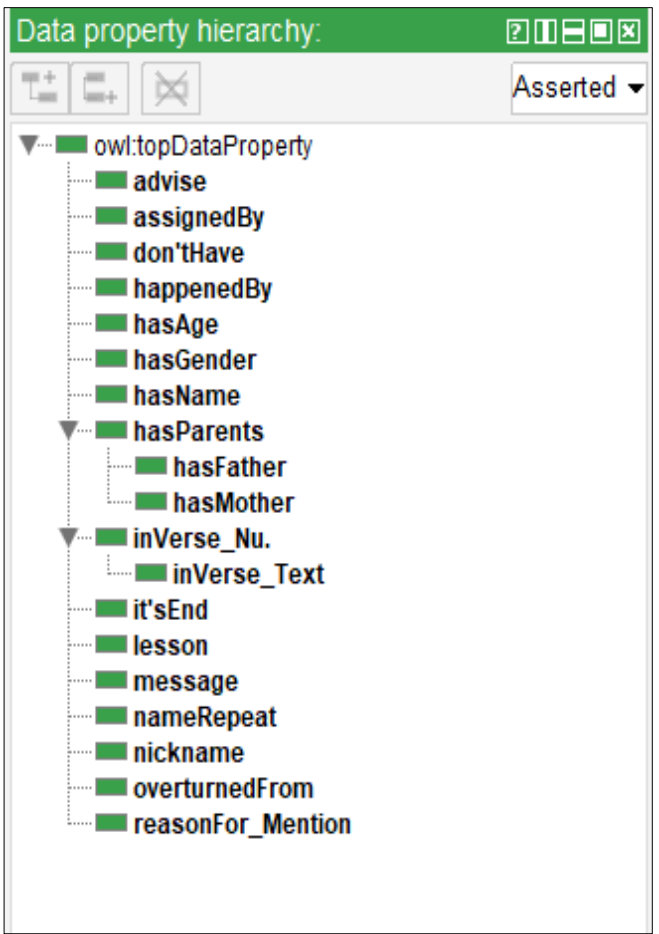

Figure 6. Holy quranic stories datatype properties

The ontology focuses on the class of the person that contains the subclass, including Prophets class, and Messenger class, both including twenty-five Prophets and Messengers mentioned in the Holy Qur'an. The proposed ontology dealt with their lives, the places they were born, lived or sent to, the message they brought to their people, the books that God gave them, the miracles and God commands and the punishment 
that God revealed to their nations, the Qur'anic suras, and the verses in which some of the above were mentioned and some were taken from authoritative history books. Also, the Person Class contained subclasses, Infidel class, Righteous and Nation, which also ontology dealt with their lives and the most important events that occurred with them. The ontology also focused on the Animals that were mentioned in the Holy Qur'an, appeared with the Prophet or the Messenger and the reason for which the animal was mentioned, and the Qur'anic suras and its verses that mentioned some of that were cited.

After completing proposed ontology implementation, it checked and evaluated using reasoner that included in protégé editor. Now transferred to the ontology population stage. Ontology population it is the process of providing the ontology with its own individuals. Ontology mapping was used to populate this ontology. The strategy that we followed to add individuals and their classes and values of datatype property to the ontology is MappingMaster with the adoption of DSL language.

A domain-specific language (DSL) for mapping spreadsheet content to ontologies is known as MappingMaster [25]. This language is based on the Manchester OWL Syntax, which is itself an OWL DSL (an ontology description language). MappingMaster adds a new reference clause to link spreadsheet information to it. This defined clause can be used instead of any OWL-named class, individual, datatype, or literal declaration in an OWL Manchester Syntax expression. From Excel Sheets that created in Data Collection Phase including the individuals with its classes and datatype properties literal will add to the ontology using MappingMaster DSL according to the Formula shown in Figure 7. A reference to any cell in a spreadsheet is "@" such as "@A2", refers to cell A2 to adding the content of it to ontology. The last step was to test and evaluate the ontology using the SPARQL query language by asking many competency questions and as a result, the ontology answered all the competency questions well.

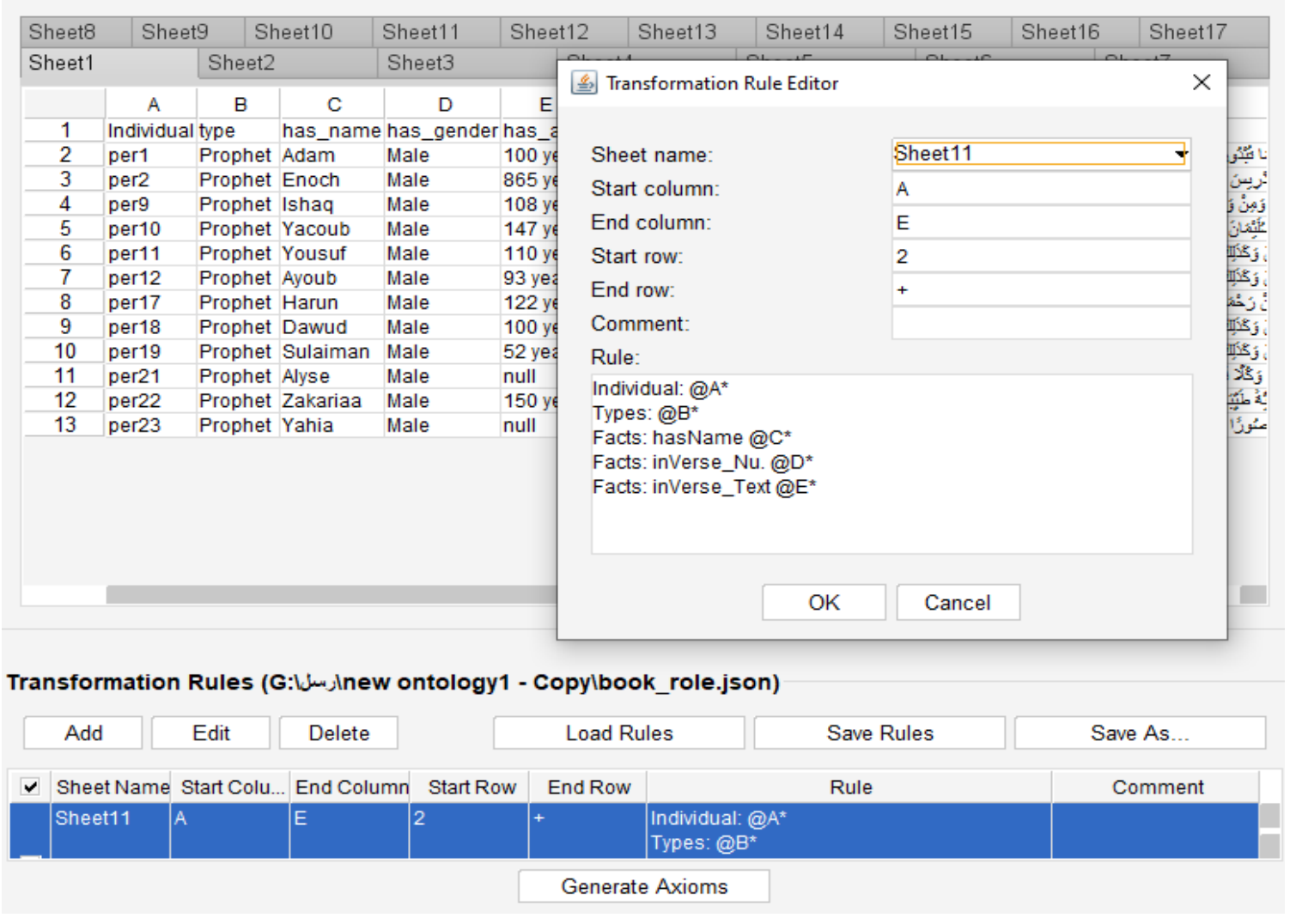

Figure 7. Mappingmaster DSL to populate ontology

\section{RESULTS AND DISCUSSION}

In Figure 8 we show a sample of individuals in Holy Quran stories ontology after represented in OWL language. In Figure 9 we show the onto the graph of Prophet class after represented in owl language using protégé and in Figure 10 we show the onto graph of event class. In Figures 11 we show some SPARQL Query to test and evaluate the Holy Quran stories ontology and the correct result of it. 


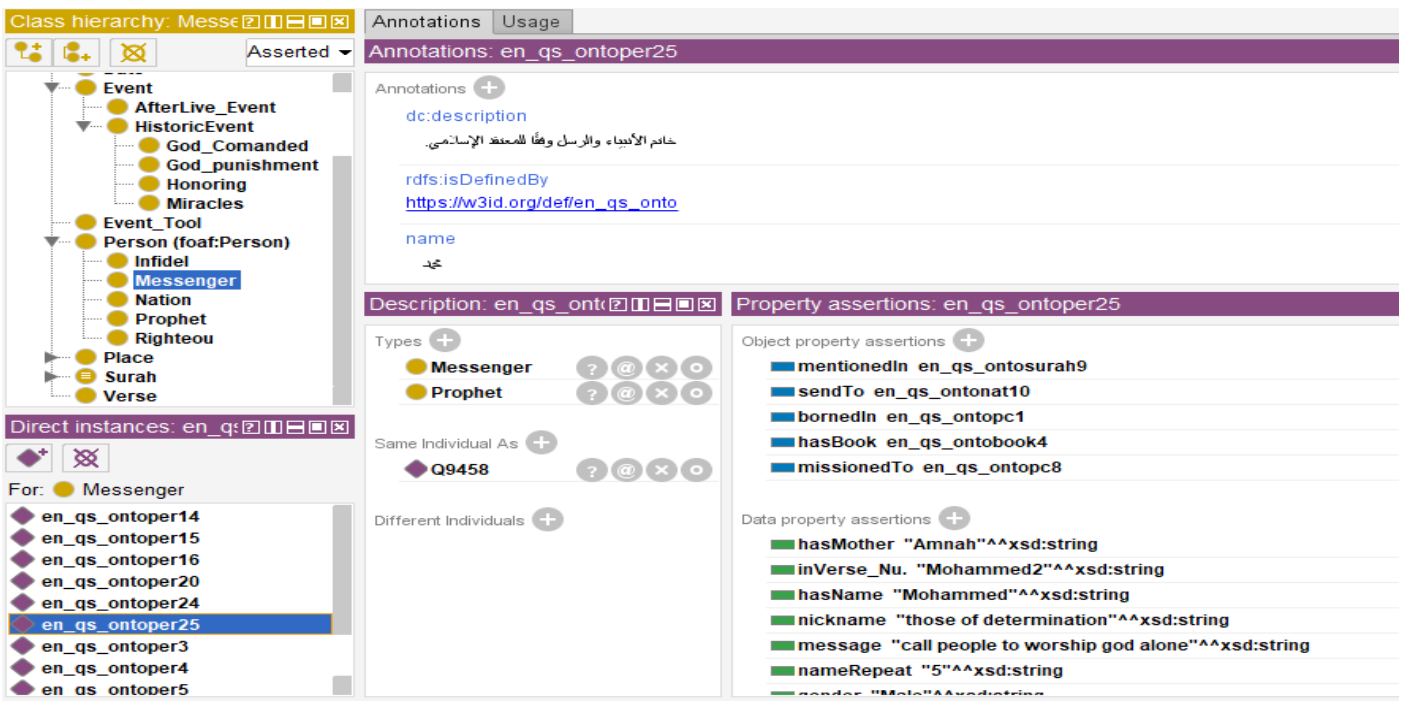

Figure 8. Sample of individuals in holy quranic stories ontology after supported in protégé

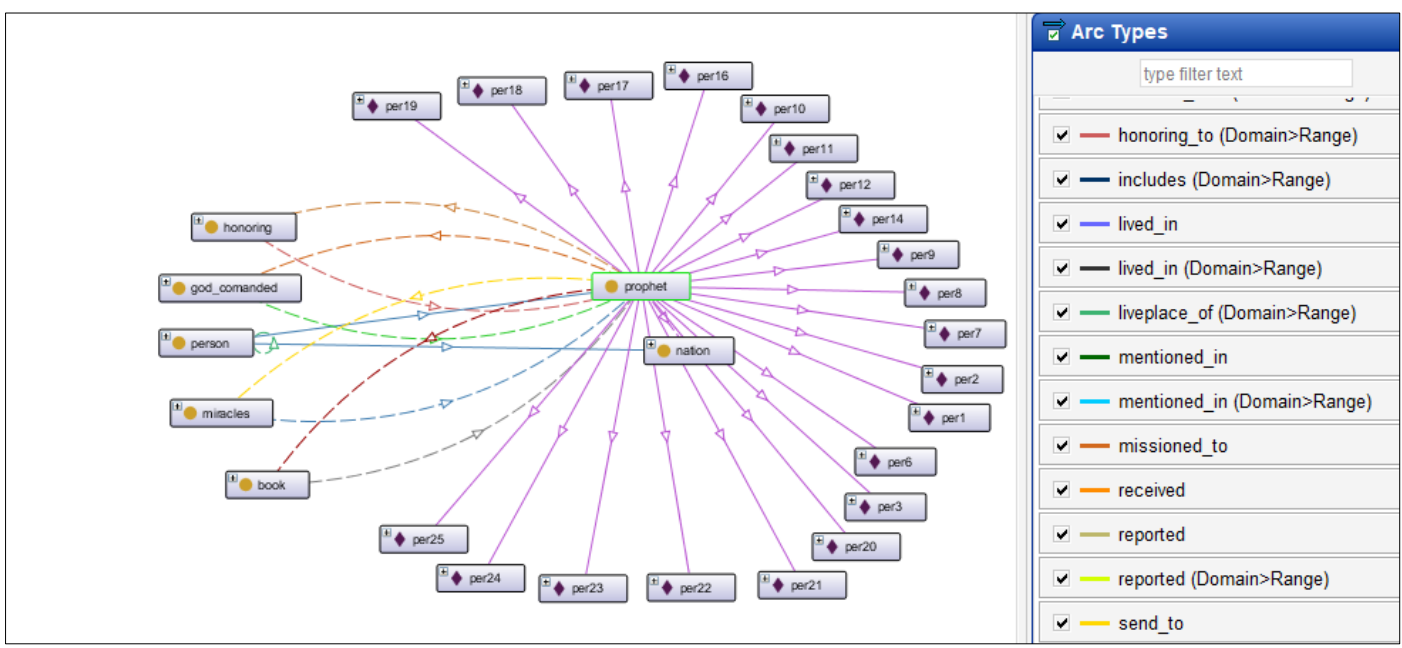

Figure 9. Onto graph of event class

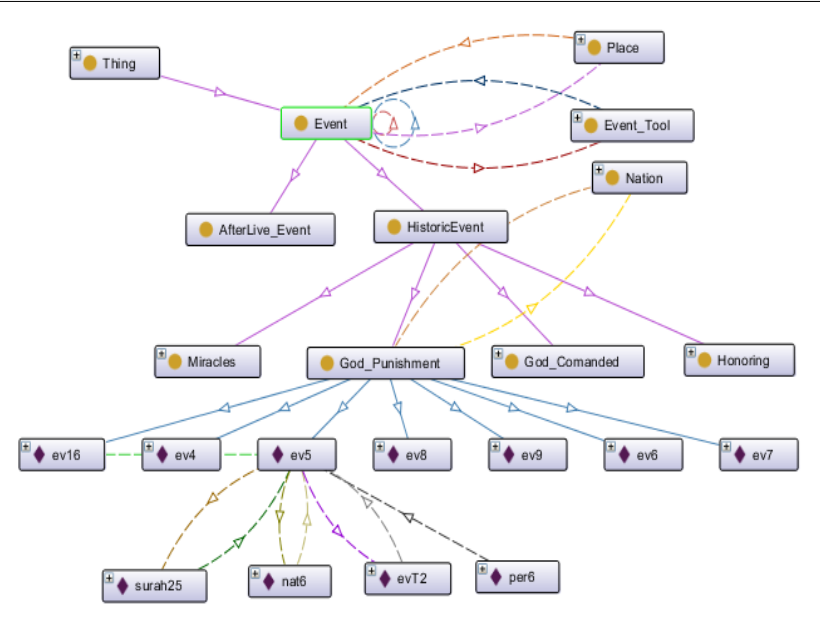

\begin{tabular}{|c|c|}
\hline $\overrightarrow{\vec{\nabla}}$ Arc Types & $\bar{x}$ \\
\hline type filter text & \\
\hline$\nabla$ - appearedWith & $\Delta$ \\
\hline$\nabla$ - bornedln (Domain>Range) & \\
\hline$\checkmark$ - bornPlaceOf (Domain>Range) & \\
\hline$\nabla$ - commandeln (Domain>Range) & \\
\hline$\nabla$ - doneBy & \\
\hline$\checkmark$ - doneBy (Domain>Range) & \\
\hline$\nabla$ - dueTo (Domain>Range) & \\
\hline$\checkmark-$ endowedTo & \\
\hline$\nabla$ gaveTo & \\
\hline$\nabla$ - generate & \\
\hline$\checkmark$ - generate (Domain>Range) & \\
\hline$\nabla$ - has individual & \\
\hline$\nabla$ - has subclass & \\
\hline
\end{tabular}

Figure 10. Onto graph of prophet class 

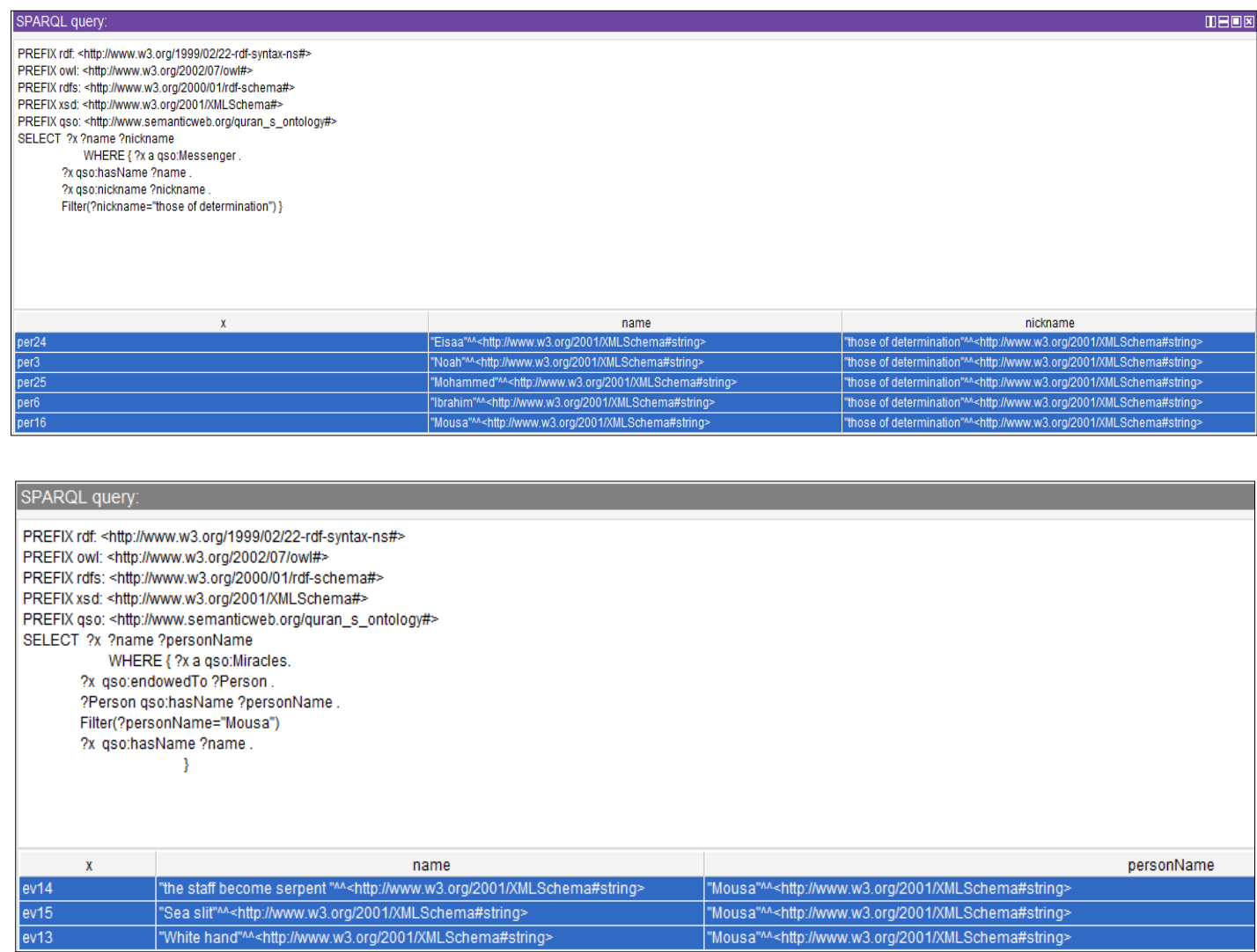

Figures 11. SPARQL queries to test holy quranic stories ontology

\section{CONCLUSION}

In this study, Quran stories ontology was written in the English language to be clear to most researchers interested in the field of the Holy Quran, and to be approved and reused later. It is considered the first ontology to be interested in the field of Quranic stories in general and it consists of 31 Classes, 35 object property and 19 data-type property and 150 individuals. The data has been structured tabularized by Excel, which is a shorthand and a repository for the components of the ontology in addition to modeling the concepts graphically using ORM. The process of populating ontology was ontology mapping approach by converting Excel Sheets to OWL using MappingMaster DSL technique. Thus, through this technique, we can provide the ontology with many individuals and with the possibility of adding new classes with their individuals to the ontology automatically from Excel Sheets. In last step SPARQL query language used to test and evaluate the proposed ontology by asking many competency questions and as a result, the ontology answered all the competency questions well. The future plans aim to develop the ontology and use it in an application through which semantic search for information and its retrieval is easy.

\section{REFERENCES}

[1] T. R. Gruber, "Toward principles for the design of ontologies used for knowledge sharing?," International journal of humancomputer studies, vol. 43, no. 5-6, pp. 907-928, doi: 10.1006/ijhc.1995.1081.

[2] N. F. Noy, and D. L. McGuinness, "Ontology development 101: A guide to creating your first ontology," Stanford knowledge systems laboratory technical report KSL-01-05, 2001.

[3] S. Saidah, N. Salim, and H. Zainal, "Islamic knowledge ontology creation," 2009 International Conference for Internet Technology and Secured Transactions, (ICITST), 2009, pp. 1-6, doi: 10.1109/ICITST.2009.5402635.

[4] S. Saad, N. Salim, H. Zainal, and Z. Muda, "A process for building domain ontology: An experience in developing Solat ontology," Proceedings of the 2011 International Conference on Electrical Engineering and Informatics, 2011, pp. 1-5, doi: 10.1109/ICEEI.2011.6021572.

[5] H. U. Khan, S. M. Saqlain, M. Shoaib, and M. S. Ramzan, "Ontology based semantic search in Holy Quran," International Journal of Future Computer and Communication, vol. 2, no. 6, pp. 570-575, 2013, doi: 10.7763/IJFCC.2013.V2.229.

[6] M. Al-Maayah, M. Sawalha, and M. Abushariah, "A proposed model for Quranic Arabic WordNet," Proceedings of the 2nd Workshop on Language Resources and Evaluation for Religious Texts, 31 May 2014, Reykjavik, Iceland, 2014, pp. 9-13.

[7] C. Brierley, M. Sawalha, and E. Atwell, "Open-source boundary-annotated corpus for Arabic speech and language processing," LREC, pp. 1011-1016, 2012. 
[8] G. A. Miller, "WordNet: a lexical database for English," Communications of the ACM, vol. 38, no. 11, pp. 39-41, 1995, doi: $10.1145 / 219717.219748$.

[9] W. Alromima, I. F. Moawad, R. Elgohary, and M. Aref, "Ontology-based model for Arabic lexicons: An application of the place nouns in the Holy Quran," 2015 11th International Computer Engineering Conference (ICENCO), 2015, pp. 137-143, doi: 10.1109/ICENCO.2015.7416338.

[10] M. Alqahtani, and E. Atwell, “Arabic Quranic search tool based on ontology,” International Conference on Applications of Natural Language to Information Systems, vol. 9612, 2016, pp. 478-485, doi: 10.1007/978-3-319-41754-7_52.

[11] S. K. Hamed and M. Ab Aziz, "A question answering system on Holy Quran translation based on question expansion technique and neural network classification," Journal of Computer Science, vol. 12, no. 3, pp. 169-177, 2016, doi: 10.3844/jessp.2016.169.177.

[12] H. A. Al-Sanasleh and B. H. Hammo, "Building domain ontology: Experiences in developing the prophetic ontology form Quran and hadith," 2017 International Conference on New Trends in Computing Sciences (ICTCS), 2017, pp. 223-228, doi: 10.1109/ICTCS.2017.35.

[13] N. Suryana, M. A. Azmi, and F. S. Utomo, "Quran ontology: Review on recent development and open research issues," Journal of Theoretical and Applied Information Technology, vol. 96, no. 3, pp. 568-581, 2018.

[14] F. S. Utomo, N. Suryana, and M. S. Azmi, "New instances classification framework on Quran ontology applied to question answering system," TELKOMNIKA Telecommunication, Computing, Electronics and Control, vol. 17, no. 1, pp. 139-146, 2019, doi: 10.12928/TELKOMNIKA.v17i1.9794.

[15] T. Halpin, "Object-role modeling fundamentals: A practical guide to data modeling with ORM," Technics Publications; First edition, 2015.

[16] L. Taylor, L. and S. Sharma, "Model composition via object-role modeling," SoutheastCon 2018, 2018, pp. 1-7, doi: 10.1109/SECON.2018.8478867.

[17] M. Jarrar, "Mapping ORM into the SHOIN/OWL description logic," OTM Confederated International Conferences "On the Move to Meaningful Internet Systems", vol. 4805, 2007, pp. 729-741, doi: 10.1007/978-3-540-76888-3_95.

[18] H. M. Wagih, D. S. El-Zanfaly, and M. M. Kouta, "Mapping object role modeling 2 schemes to OWL2 ontologies," $20113 r d$ International Conference on Computer Research and Development, vol. 3, 2011, pp. 126-132, doi: 10.1109/ICCRD.2011.5764262.

[19] R. Subhashini, and J. Akilandeswari, "A survey on ontology construction methodologies," International Journal of Enterprise Computing and Business Systems, vol. 1, no. 1, pp. 60-72, 2011.

[20] K. Liu, W. R. Hogan, and R. S. Crowley, "Natural language processing methods and systems for biomedical ontology learning," Journal of Biomedical Informatics, vol. 44, no. 1, pp. 163-179, 2011, doi: 10.1016/j.jbi.2010.07.006.

[21] M. S. García, D. V. Ayala, and I. H. Pineda, "An overview of ontology learning tasks," Computacion y Sistemas, vol. 22, no. 1, pp. 137-146, 2018, doi: 10.13053/cys-22-1-2790.

[22] R. Gonçalves, J. Hardi, M. Horridge, S. Tu, and M. Musen. "Protégé." Protege.stanford.edu. http://protege.stanford.edu/ (Accessed Sep. 2, 2020)

[23] A. R. Yauri, R. A. Kadir, A. Azman, and M. A. A. Murad, "Quranic verse extraction base on concepts using OWL-DL ontology," Research Journal of Applied Sciences, Engineering and Technology, vol. 6, no. 23, pp. 4492-4498, 2013, doi: 10.19026/rjaset.6.3457.

[24] J. Hebeler, M. Fisher, R. Blace, A. P.-Lopez, and M. Dean, “Semantic web programming,” John Wiley \& Sons, 2011.

[25] M. O'Connor. "MappingMasterDSL." MappingMasterDSL. Github.com. https://github.com/protegeproject/mappingmaster/wiki/MappingMasterDSL (Accessed 15 Dec. 15, 2020). 